Provided for non-commercial research and education use. Not for reproduction, distribution or commercial use.

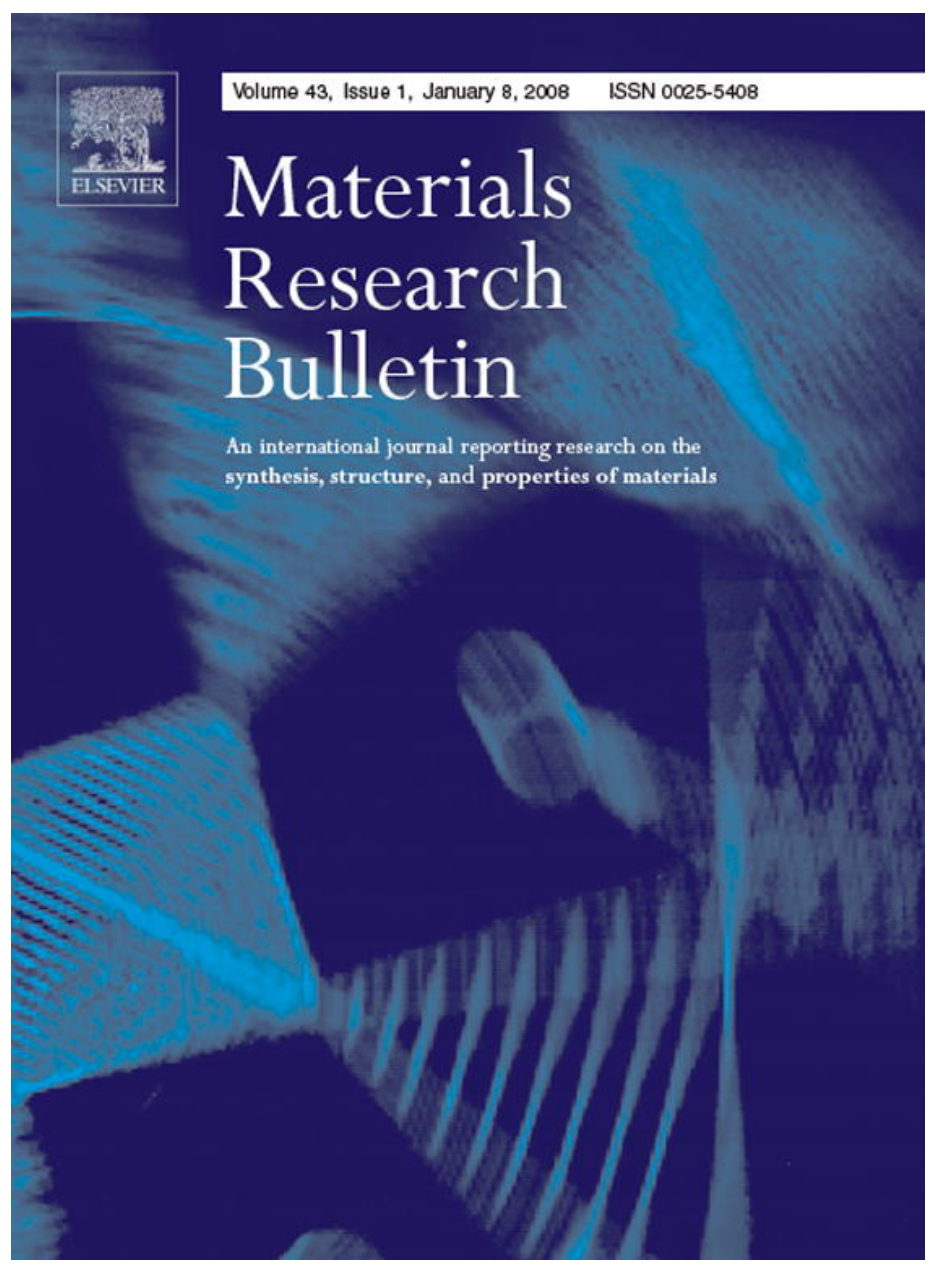

This article was published in an Elsevier journal. The attached copy

is furnished to the author for non-commercial research and education use, including for instruction at the author's institution, sharing with colleagues and providing to institution administration.

Other uses, including reproduction and distribution, or selling or licensing copies, or posting to personal, institutional or third party websites are prohibited.

In most cases authors are permitted to post their version of the article (e.g. in Word or Tex form) to their personal website or institutional repository. Authors requiring further information regarding Elsevier's archiving and manuscript policies are encouraged to visit: 


\title{
Controlled preparation of hollow zinc oxide microspheres from aqueous solution using hexamethylenetetramine and cysteine
}

\author{
Daniel Weinzierl $^{\mathrm{a}}$, Didier Touraud ${ }^{\mathrm{a}}$, Alois Lecker ${ }^{\mathrm{b}}$, Arno Pfitzner ${ }^{\mathrm{b}}$, Werner Kunz ${ }^{\mathrm{a}, *}$ \\ anstitute of Physical and Theoretical Chemistry, University of Regensburg, 93040 Regensburg, Germany \\ ${ }^{\mathrm{b}}$ Institute of Inorganic Chemistry, University of Regensburg, 93040 Regensburg, Germany \\ Received 11 September 2006; received in revised form 1 February 2007; accepted 7 February 2007
}

Available online 11 February 2007

\begin{abstract}
Zinc oxide particles were synthesized by precipitation from an aqueous solution of zinc nitrate tetrahydrate, $R-(+)$-cysteine and hexamethylenetetramine (HMTA, urotropine). Hollow microspheres of $\mathrm{ZnO}$-cysteine hybrid material with a diameter of ca. $1 \mu \mathrm{m}$ and a wall thickness ca. $50 \mathrm{~nm}$ were obtained. After heating up to $850{ }^{\circ} \mathrm{C}$ pure $\mathrm{ZnO}$ microspheres of roughly the same size were formed. The particles were characterized by XRD, SEM, FT-IR and TGA.
\end{abstract}

(C) 2007 Elsevier Ltd. All rights reserved.

Keywords: A. Amorphous materials; A. Composites; A. Oxides, B. Crystal growth; C. X-ray diffraction

\section{Introduction}

Zinc oxide crystallizes in the hexagonal wurtzite structure type having II-IV compound semiconductor properties with a wide and direct band gap of $3.37 \mathrm{eV}$ and a large exciton binding energy of $60 \mathrm{meV}$ [1]. It has various potential applications, major interests concern chemical sensors [2,3], varistors [4,5], transducers [6], pigments [7], components for the pharmaceutical and cosmetic industries [8,9], catalysis [10,11] and electrodes for solar cells [12]. Huang et al. [13] observed a UV-laser emisson at room temperature using $\mathrm{ZnO}$ nanowires and thus showed the potential use as UVlaser material. All these applications make use of the unique optical, chemical and electrical properties of $\mathrm{ZnO}$ powders, which strongly depend on its particle size, size distribution, morphology and so on [14]. So developing new easy and cheap routes to synthesize monodispersed $\mathrm{ZnO}$ micro- and nanoparticles has great importance both in fundamental and application points of view. There are many reports in literature concerning the synthesis of $\mathrm{ZnO}$ particles [15-21]. Utilizing these methods, $\mathrm{ZnO}$ of a great variety of morphologies in the micro- and nanoscale has been successfully prepared, including rod-like, hexagonal prism-shaped, flower-like and needle-like. Recently, even polyhedral cages [22], nanorings and nanohelices [23] were produced. However, there are only few reports about spherical ZnO particles: Chittofrati and Matijevic [24] reported the synthesis of spherulitic ZnO particles in the presence of triethanolamine in aqueous solution. Wang et al. [25] prepared spherulitic ZnO microspheres selfassembled by hexagonal nanoplates in a methanol-water solution of zinc acetate dihydrate and hexamethylenetetramine. Finally, Andrés Vergés et al. [26] reported amorphous spherical $\mathrm{ZnO}$ particles in the early stages of the

\footnotetext{
* Corresponding author. Tel.: +49 941943 4044; fax: +49 9419434532.

E-mail address: Werner.Kunz@chemie.uni-regensburg.de (W. Kunz).
} 
evolution of rod-like $\mathrm{ZnO}$ particles using zinc nitrate, HMTA and water. However, no attempt was made to control the sphere size and shape of the particles.

Here, we report the synthesis of spherical amorphous particles of $\mathrm{ZnO}$ with controllable size using zinc nitrate, hexamethylenetetramine, $R-(+)$-cysteine and water. This study is part of a systematic investigation concerning the influence of amino acids on crystallization phenomena and the structuring and morphology of the resulting material.

\section{Experimental}

Zinc nitrate tetrahydrate, $\mathrm{Zn}\left(\mathrm{NO}_{3}\right)_{2} \cdot 4 \mathrm{H}_{2} \mathrm{O}$, HMTA (hexamethylenetetramine) and $R$-(+)-cysteine were purchased from Merck and all were at least of reagent grade. Water was purified in a Millipore system prior to use.

In a typical experiment, $523 \mathrm{mg}$ zinc nitrate tetrahydrate $(2.0 \mathrm{mmol}), 707 \mathrm{mg} R$-(+)-cysteine $(5.8 \mathrm{mmol})$ and $280 \mathrm{mg}$ HMTA $(2.0 \mathrm{mmol})$ were put in a $100 \mathrm{~mL}$ flask and $60 \mathrm{~mL}$ water were added. Then the $\mathrm{pH}$ was adjusted to 6.3 using a $1 \mathrm{M} \mathrm{NaOH}$ solution and water added to $80 \mathrm{~mL}$. This solution was filtered with $0.22 \mu \mathrm{m}$ Millipore filters for two times. The reaction solution containing $\mathrm{Zn}\left(\mathrm{NO}_{3}\right)_{2}$ and cysteine was heated to $90{ }^{\circ} \mathrm{C}$ and then HMTA dissolved in $20 \mathrm{~mL}$ of distilled water was added to result in a total volume of $100 \mathrm{~mL}$. After the solution became turbid (typically within less than $1 \mathrm{~min}$ ), it was further kept at $90{ }^{\circ} \mathrm{C}$ for $90 \mathrm{~min}$ and was then immediately cooled in an ice water bath. After the reaction was finished, the flask was cooled in an ice bath for $5 \mathrm{~min}$. The precipitated powder was collected by filtration $\left(0.22 \mu \mathrm{m}\right.$ filters), washed several times with Millipore water and dried in an oven at $60{ }^{\circ} \mathrm{C}$ for several days.

Dried powders were analysed by scanning electron microscopy, SEM (Zeiss DSM 950), X-ray diffraction, XRD (STOE \& CIE, STADI P), Fourier transform infrared spectroscopy, FT-IR (Jasco FT/IR-610) and thermo-gravimetric analysis, TGA (Perkin-Elmer TGA7). The samples were coated with gold for SEM. XRD measurements in transmission setup were performed using $\mathrm{Cu} \mathrm{K \alpha} \alpha_{1}$ radiation $(\lambda=1.540598 \AA)$ monochromated with a germanium single crystal in the range of $8^{\circ}<2 \theta<90^{\circ}$ at a scanning speed of $0.8^{\circ} / \mathrm{min}$. The samples were spread on a mylar sample holder. For the infrared spectra, the samples were diluted with $\mathrm{KBr}$ and the spectra were recorded in diffuse reflection mode from 4000 to $400 \mathrm{~cm}^{-1}$ at a resolution of $2 \mathrm{~cm}^{-1}$. TGA was performed from 50 to $900{ }^{\circ} \mathrm{C}$ at a heating rate of $10 \mathrm{~K} / \mathrm{min}$ in an oxygen atmosphere.

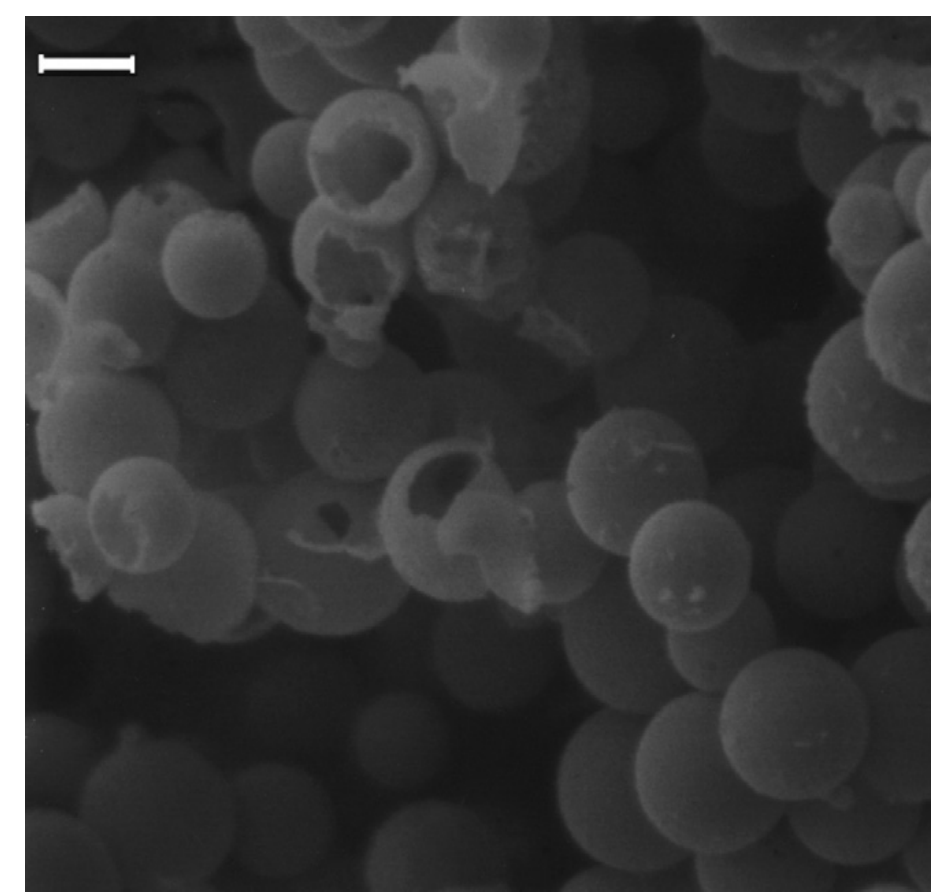

Fig. 1. SEM micrographs of monodisperse spheres synthesized at $90{ }^{\circ} \mathrm{C}$, heated for $90 \mathrm{~min}$ after turbidity occurred $(\mathrm{c}(\mathrm{Zn})=0.02 \mathrm{~mol} / \mathrm{L}$, $\mathrm{c}($ HMTA $)=0.02 \mathrm{~mol} / \mathrm{L}, \mathrm{c}($ cysteine $)=0.05 \mathrm{~mol} / \mathrm{L})$, the white bar is $1 \mu \mathrm{m}$. 


\section{Results and discussion}

SEM pictures like the one shown in Fig. 1 revealed the presence of hollow spherical particles with a diameter of ca. $1 \mu \mathrm{m}$, a shell thickness of about $50 \mathrm{~nm}$ and a near size distribution. Several spheres were broken so that the hollowness of the spheres clearly appeared.

To further characterize the obtained hollow spheres several other experiments were performed. Fig. 2 gives the Xray diffraction pattern of the particles (Fig. 2a), their FT-IR spectrum (Fig. 2b), the IR spectrum of pure cysteine for comparison (Fig. 2c) and the TGA curve (Fig. 2d) of the microsphere powder formed by ZnO-cysteine complexes. $\mathrm{XRD}$ proves that the microspheres are completely amorphous, the maxima in the diffraction curve are due to the sample holder.

The peaks at 1350 and $856 \mathrm{~cm}^{-1}$ present in the IR spectrum indicate that the spheres contain $\mathrm{NO}_{3}{ }^{-}$ions. Typical IR-absorptions for $\mathrm{NO}_{3}{ }^{-}$ions are between 1380 and $1350 \mathrm{~cm}^{-1}$, and another one between 860 and $800 \mathrm{~cm}^{-1}$ [27].

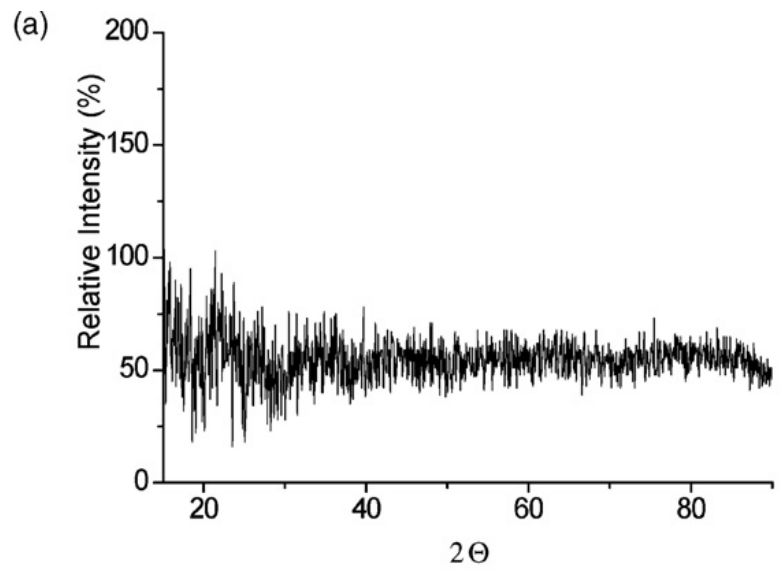

(b)

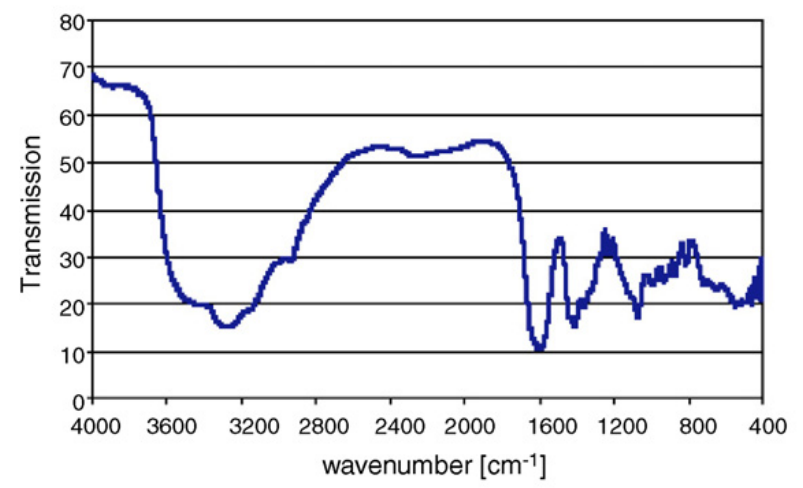

(1)

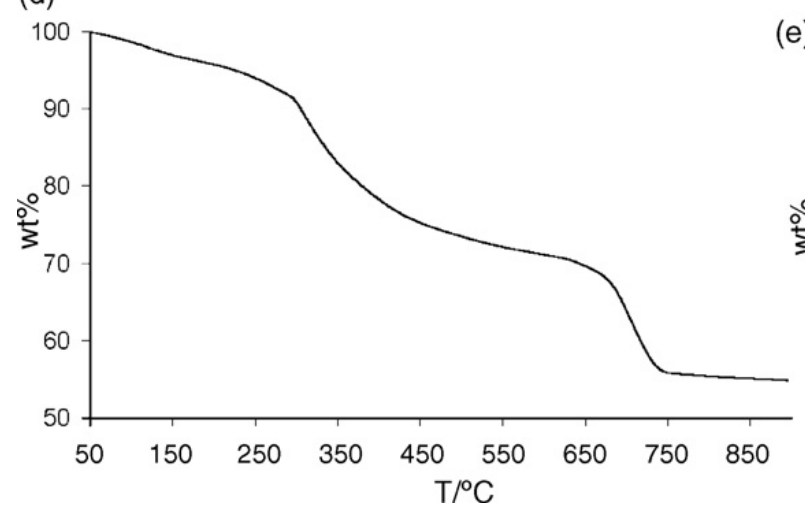

(c)
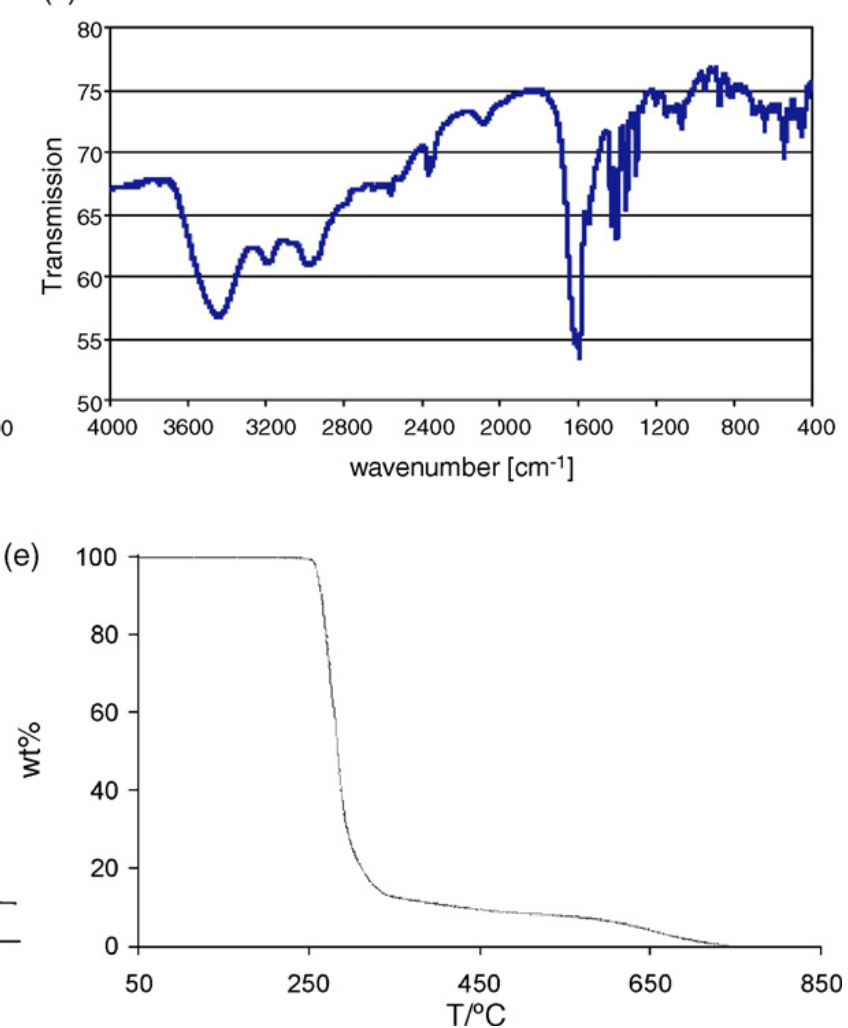

Fig. 2. (a) XRD pattern, (b) FT-IR pattern of monodisperse ZnO-cysteine powders synthesized at $90{ }^{\circ} \mathrm{C}$, heated for 90 min after turbidity occurred $(\mathrm{c}(\mathrm{Zn})=0.02 \mathrm{~mol} / \mathrm{L}, \mathrm{c}(\mathrm{HMTA})=0.02 \mathrm{~mol} / \mathrm{L}, \mathrm{c}($ cysteine $)=0.05 \mathrm{~mol} / \mathrm{L})),(\mathrm{c})$ IR spectrum of pure cysteine, $(\mathrm{d})$ the TG analysis of the microparticles and (e) of pure cysteine. 


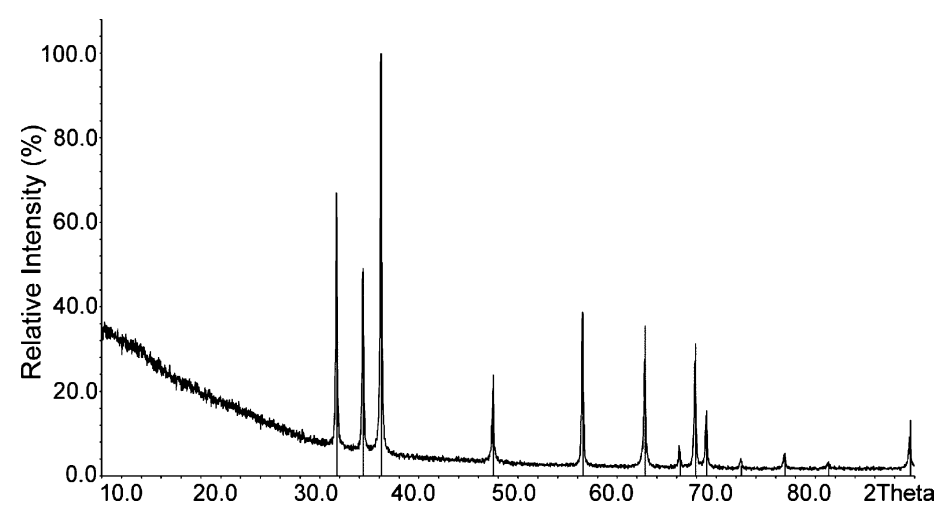

Fig. 3. The XRD analysis after heating the sample to $850{ }^{\circ} \mathrm{C}$ shows the characteristics of wurtzite type $\mathrm{ZnO}$.

These nitrate absorptions are still present after thorough washing of the samples. The persistence of the characteristic nitrate absorptions in the FT-IR spectra suggests that nitrate ions are either strongly adsorbed onto the surface of the hollow microspheres or incorporated into the material. The spectrum of the particles shows also a significant contribution from cysteine, cf. Fig. 2c. Because of the superposition of signals from different components it is difficult to quantify the relative amount of each component from the IR spectrum.

Fig. $2 \mathrm{~d}$ shows a massive weight loss of nearly $40 \%$ in the TGA, suggesting a composite material for the spheres. The TGA is qualitatively similar to the weight loss of a pure cysteine sample that was done for comparison, see Fig. 2e. It therefore can be concluded that mainly cystein is decomposed and finally converted to $\mathrm{CO}_{2}$ at high temperatures.

After thermal treatment XRD peaks characteristic of wurtzite type $\mathrm{ZnO}$ appear, see Fig. 3.

EDX analysis showed that the initial hollow microspheres (before TGA analysis) contained a significant amount of sulphur and of carbon. These results indicate that the hollow microspheres are a composite material of cysteine and zinc oxide with nitrate ions strongly adsorbed on the surface or incorporated into the material. The composite material may be made of stable complexes of zinc with cysteine as ligand. Amino acids are known to form complexes with zinc [28-30] and zinc complexes of cysteine with a composition of 1:1 are also well known in literature [31-34]. Although a quantitative EDX analysis of the powder is difficult to obtain, the EDX result is in rough agreement with such a composition.

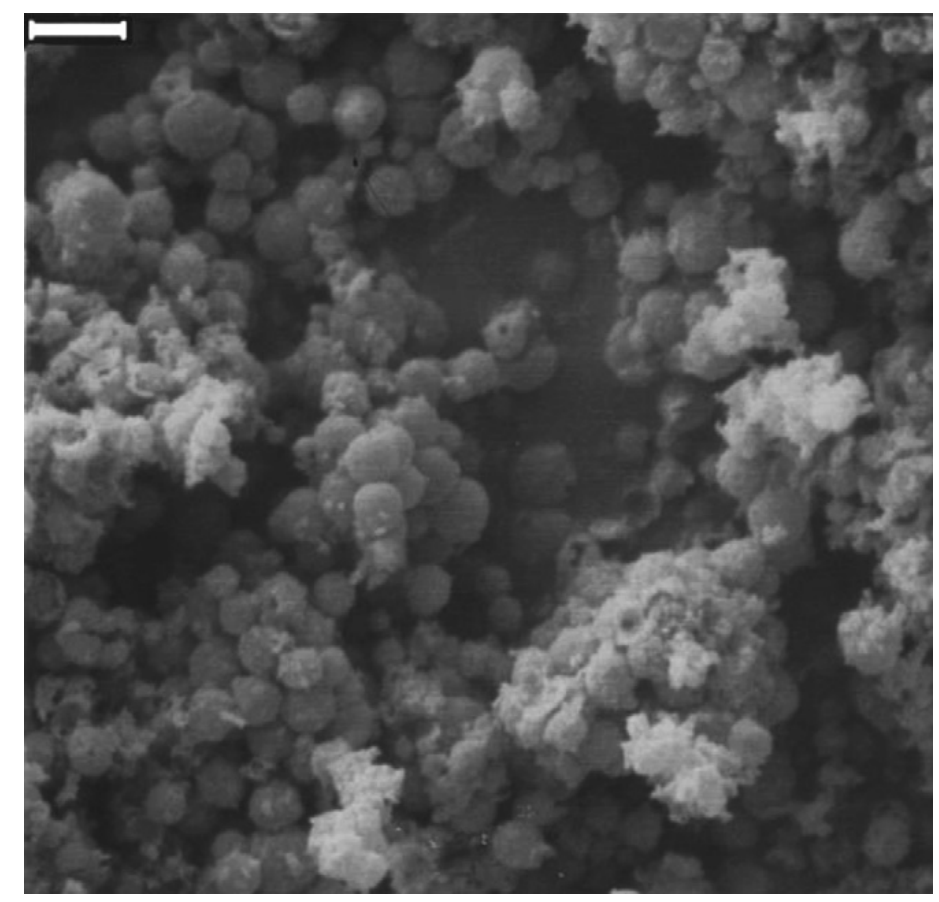

Fig. 4. SEM image of $\mathrm{ZnO}$ microspheres after buring the organic material at $850{ }^{\circ} \mathrm{C}$. The scale bar is $2 \mu \mathrm{m}$. 


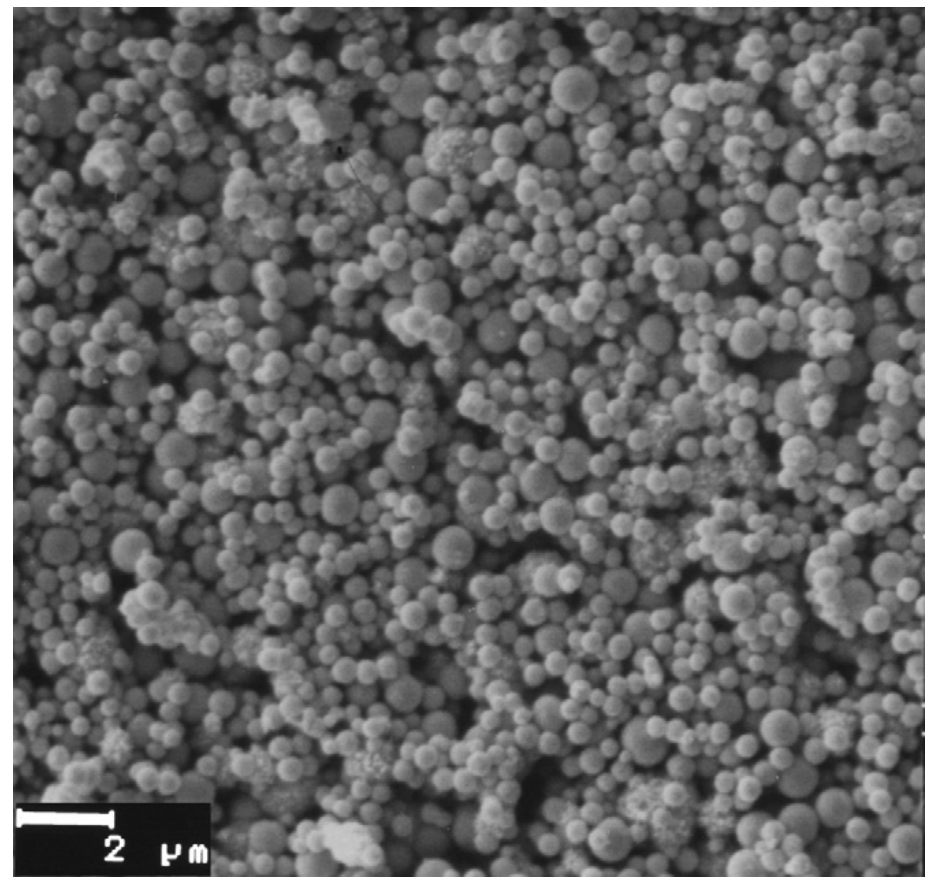

Fig. 5. SEM image of $\mathrm{ZnO}-$ cysteine microspheres with diameters ranging from 0.2 to $0.8 \mu \mathrm{m}$, synthesized at $70{ }^{\circ} \mathrm{C}$.

EDX analyses of the powder after heating to $850{ }^{\circ} \mathrm{C}$ were also performed. Only $\mathrm{Zn}$ and $\mathrm{O}$ were found in nonnegligible amounts. SEM showed that the shape of the particles did not significantly change, see Fig. 4 . We conclude that the remaining hollow spheres consist of more or less pure $\mathrm{ZnO}$.

Further, we found that the size of the amorphous spheres depended on the precipitation temperature and time. For example, heating to $70{ }^{\circ} \mathrm{C}$ during $30 \mathrm{~min}$ produces a sample containing spheres with diameters of 0.2 to $0.8 \mu \mathrm{m}$ (Fig. 5). At $90^{\circ} \mathrm{C}$, the microspheres slowly grow from approximately $0.4 \mu \mathrm{m}$ (immediately after turbidity occurs) to approximately $1 \mu \mathrm{m}$ after 90 min of heating.

Finally, a UV spectrum of the hollow $\mathrm{ZnO}$ particles (after burning the cysteine at high temperatures) was recorded, see Fig. 6. The spectrum is typical for macrocrystalline $\mathrm{ZnO}$ [35].

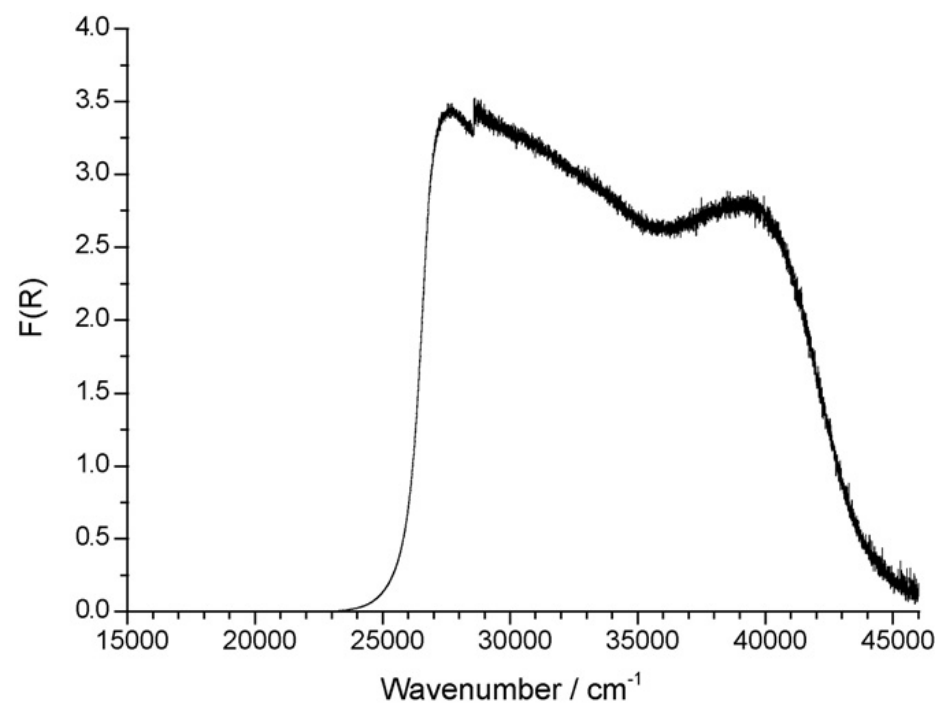

Fig. 6. UV spectrum of the $\mathrm{ZnO}$ particles. 


\section{Conclusion}

Hollow, amorphous $\mathrm{ZnO}$ microspheres have been synthesized using a simple aqueous solution route with zinc nitrate and HMTA and taking advantage of special $\mathrm{Zn}$-cysteine interactions. It is shown that the particle size depends on temperature and precipitation time.

\section{Acknowledgments}

We particularly thank Prof. Barry W. Ninham, ANU, Canberra, for having given us the idea to investigate the influence of amino acids on the crystallization of oxides and for many discussions about this topic. We also thank Ulrike Schiessl, Institute of Inorganic Chemistry, University of Regensburg, for her help in XRD and SEM measurements and Dr. Rainer Müller, Institute of Physical and Theoretical Chemistry for recording the IR spectrum of pure cysteine. The UV spectrum was made in Prof. Josef Breu's lab at Bayreuth University, Germany. We also acknowledge his help.

\section{References}

[1] (a) D.C. Reynolds, D.C. Look, B. Jogai, J.E. Hoelscher, J. Appl. Phys. 88 (2000) 2152;

(b) E.M. Wong, P.C. Searson, Appl. Phys. Lett. 74 (1999) 2939.

[2] G. Heiland, Am. Ceram. Soc. Bull. 74 (5) (1990) 780.

[3] K. Tsukamoto, C. Yamagishi, K. Koumoto, H. Yanagida, H. J. Mater. Sci. 19 (1984) 2493.

[4] M. Matsuoka, in: L.M. Levinson (Ed.), Adv. Ceram., vol. 1, American Ceramic Society Inc., Columbus, Ohio, 1981, pp. 290-308.

[5] P.Q. Mantas, J.L. Baptista, J. Eur. Ceram. Soc. 5 (1989) 237.

[6] F.C.M. Van de Pol, Am. Ceram. Soc. Bull. 69 (12) (1990) 1959.

[7] F.A. Sigoli, M.R. Davolos, M. Jafelicci Jr., J. Alloys Compd. 262-263 (1997) 292.

[8] O. Yamamoto, Int. J. Inorg. Mater. 3 (2001) 643.

[9] H. Akiyama, O. Yamasaki, H. Kanzaki, J. Tada, J. Arata, J. Dermatol. Sci. 17 (1998) 67.

[10] C.A.K. Gouvêa, F. Wypych, S.G. Moraes, N. Durán, N. Nagata, P. Peralta-Zamora, Chemosphere 40 (2000) 433.

[11] W.F. Elseviers, H. Verelst, Fuel 78 (1999) 601.

[12] K. Keis, C. Bauer, G. Boschloo, A. Hagfeldt, K. Westermark, H. Rensmo, H.J. Siegbahn, Photochem. Photobiol. A 148 (2002) 57.

[13] M.H. Huang, S. Mao, H. Feick, H. Yan, Y. Wu, H. Kind, E. Weber, R. Russo, P. Yang, Science 292 (2001) 1897.

[14] D. Li, H. Haneda, Chemosphere 51 (2003) 129.

[15] J. Zhang, L. Sun, J. Yin, H. Su, C. Liao, Yan, Chem. Mater. 14 (2002) 4172.

[16] B. Pal, M. Sharon, Mater. Chem. Phys. 76 (2002) 82.

[17] D. Kaneko, H. Shouji, T. Kawai, K. Kon-No, Langmuir 16 (2000) 4086.

[18] J.Y. Lao, J.Y. Huang, D.Z. Wang, Z.F. Ren, Nano Lett. 3 (2003) 235.

[19] W.-J. Li, E.-W. Shi, M.-Y. Tian, W.Z. Zhong, Z.-W. Yin, J. Mater. Res. 14 (1999) 1532.

[20] A.P.A. Oliveira, J.-F. Hochepied, F. Grillon, M.-H. Berger, Chem. Mater. 15 (2003) 3202.

[21] C. Pacholski, A. Kornowski, H. Weller, Angew. Chem. 41 (2002) 1189.

[22] P.X. Gao, Z.L. Wang, J. Am. Chem. Soc. 125 (2003) 11299.

[23] X.Y. Kong, Z.L. Wang, Nano Lett. 3 (12) (2003) 1625.

[24] A. Chittofrati, E. Matijevic, Colloids Surf. 48 (1990) 65.

[25] H. Wang, C. Xie, D. Zeng, Chem. Lett. 34 (2) (2005) 260.

[26] M. Andrés Vergés, A. Mifsud, C.J.J. Serna, Chem. Soc. Faraday Trans. 86 (1990) 959.

[27] M. Hesse, H. Meier, B. Zeeh, Spektroskopische Methoden in der organischen Chemie, fifth ed., Georg Thieme Verlag, Stuttgart, 1995.

[28] M. Rombach, M. Gelinsky, H. Vahrenkamp, Inorgan. Chim. Acta 334 (2002) 25.

[29] C.A. Steren, R. Calvo, O.E. Piro, B.E. Rivero, Inorg. Chem. 28 (1989) 1933.

[30] B. Dolinska, Il Farmaco 56 (2001) 737.

[31] P. Gockel, H. Vahrenkamp, A.D. Zuberbuehler, Helvetica Chim. Acta 76 (1) (1993) 511.

[32] R. Vogler, M. Gelinsky, L.F. Guo, H. Vahrenkamp, H. Inorg. Chim. Acta 339 (2002) 1.

[33] D.A. Newsome, D. Tate, D. U.S. Patent Appl. Publ., US 2004122088A1 20040624 (2004).

[34] D.A. Newsome, D. Tate, D. U.S. Patent Appl. Publ., US 6586611 B1 20030701 (2003).

[35] A. van Dijken, E.A. Meulenkamp, D. Vanmaekelbergh, A. Meijerink, J. Phys. Chem. B 104 (2000) 1715. 